\title{
Copper Ion Complex Formation of a Dicarboxylic Acid-Containing Polypeptide
}

\author{
Yoshitomo Nagata, Hisashi Kuroda, Takatoshi Kinoshita, \\ Akira Takizawa, Yoshiharu Tsujita, \\ and Hiroaki Yoshimizu \\ Department of Materials Science \& Engineering, \\ Nagoya Institute of Technology, \\ Gokiso-cho, Showa-ku, Nagoya 466, Japan
}

(Received April 26, 1993)

\begin{abstract}
A side-chain dicarboxylic acid-containing polypeptide was prepared by introduction of L-glutamic acid to poly(L-glutamic acid) in the side chains. The polypeptide showed extremely high ability for copper ion complex formation. Complex formation induced the stabilization of $\alpha$-helix structure of the polypeptide, which enabled $\mathrm{Cu}-\mathrm{Cu}$ interactions in the side-chain region.

KEY WORDS Biomimetic System / Polypeptide / Dicarboxylic Acid / $\mathrm{Cu}^{2+}$ Ion Complex / Random Ciol to $\alpha$-Helix Transition / $\mathrm{Cu}-\mathrm{Cu}$ Interaction / dimeric Structure of $\mathrm{Cu}^{2+}$-Acetate Type /
\end{abstract}

Biological activity of metalloproteins is induced by specific complexation with metal ions. $^{1-11}$ For example, osteocalcin, a dicarboxlic acid-containing protein of bone, contains a series of $\gamma$-carboxyglutamic acid (Gla) residues along the "Gla helix" as specific binding sites for $\mathrm{Ca}^{2+}$ ions. ${ }^{12,13}$ The transition to the $\alpha$-helical structure, essential for biological activity, of osteocalcin can be regulated by millimolar levels of $\mathrm{Ca}^{2+}$ ion. ${ }^{12}$ In this study, therefore, an artificial model polypeptide containing dicarboxylic acid residues similar to Gla was prepared and complex formation of the polypeptide with metal ion and induced conformational changes of the polypeptide were investigated by absorption and circular dichroism (CD) methods.

First, the copper ion complex formation was studied because complex formation behavior between $\mathrm{Cu}^{2+}$ ion and carboxylic acidcontaining polypeptide such as poly(L-glutamic acid) (PGA) has been well characterized. . $^{\text {4-21 }}$ The present paper indicates that the complex formation ability of the dicarboxylic acid containing polypeptide to $\mathrm{Cu}^{2+}$ is 50 times that of PGA. The induced transition to the $\alpha$-helical structure may be explained as due to the neutralization effect of $\mathrm{Cu}^{2+}$ and $\mathrm{Cu}-\mathrm{Cu}$ dimeric linkage on the periphery of the polypeptide backbone.

\section{EXPERIMENTAL}

\section{Materials}

A side-chain dicarboxylic acid-containing polypeptide, poly $(\gamma$-L-glutamyl-L-glutamic acid-co-L-glutamic acid) (GGA/GA, Scheme 1), was prepared by introduction of L-glutamic acid to poly(L-glutamic acid) (PGA, $M_{v}=$ $\left.1.19 \times 10^{5}\right)$ in the side chains. $^{22}$ PGA was obtained by the saponification of $\operatorname{poly}(\gamma-$ methyl L-glutamate) $\left(\mathrm{PMG}, M_{v}=1.50 \times 10^{5}\right)$

* To whom correspondence should be addressed. 


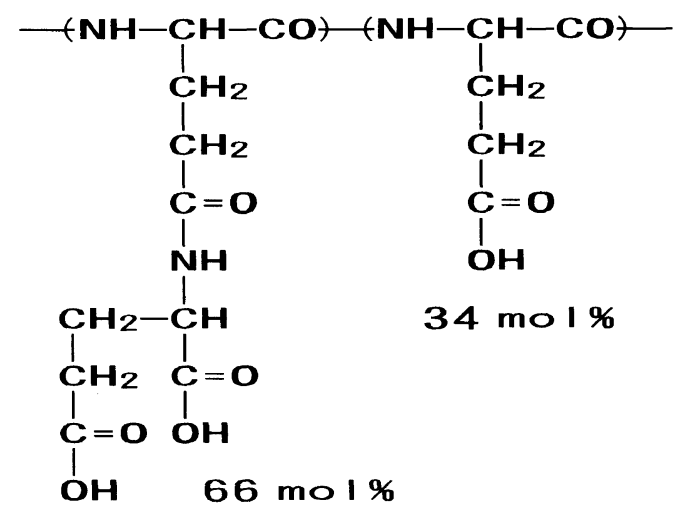

Scheme 1. GGA/GA.

(kindly provided by Ajinomoto Co., Ltd.). ${ }^{23}$ PGA (1 g) was dissolved in $N, N$-dimethylformamide (DMF, $50 \mathrm{ml})$ at $0^{\circ} \mathrm{C}$ with equimolar L-glutamic acid diethyl ester (1.9 g), 1-ethyl-3(3-dimethylaminopropyl)carbodiimide ( $1.5 \mathrm{~g})$, and 1-hydroxy- $1 H$-benzotriazole $(1.2 \mathrm{~g})$. The reaction mixture was stirred for $216 \mathrm{~h}$ at room temperature. The dimethylformamide (DMF) solution was poured into $\mathrm{HCl}$ aqueous solution ( $\approx \mathrm{pH} 2.0$ ). The residues obtained were washed with acidic solution 3 or 4 times until unreacted monomer, L-glutamic acid diethyl ester, could not be detected spectroscopically by analysis of amino group of the monomer with 7-chloro-4-nitrobenzo-2-oxa-1,3-diazole (NBD-C1, DOJINDO Lab.), ${ }^{24}$ fluorescent labeling reagent. The content of dicarboxylic acid diethyl ester residue determined by the high-resolution ${ }^{1} \mathrm{H}$ NMR analysis (Varian XL-200 spectromeater) was $66 \mathrm{~mol} \%$. Protecting ethyl esters of the dicalboxylates $(1 \mathrm{~g})$ in DMF $(25 \mathrm{ml})$ solution were hydrolyzed by $\mathrm{KOH}(0.46 \mathrm{~g})$ in mixed solution of methanol (18 ml), 2-propanol $(18 \mathrm{ml})$ and $\mathrm{H}_{2} \mathrm{O}(9 \mathrm{ml})$ at $25^{\circ} \mathrm{C}^{23}$ Complete deprotection was confirmed by ${ }^{1} \mathrm{H}$ NMR analysis.

$\mathrm{CuCl}_{2} \cdot 2 \mathrm{H}_{2} \mathrm{O}$ (Nacarai Tesque Co., Ltd.) was guaranteed reagent.

\section{Measurement}

The absorption and circular dichroism spectra of GGA/GA in aqueous solution were measured with spectrophotometer (Jasco, UVIDEC-670) and spectropolarimeter (Jasco, $\mathrm{J}-600$ ) at room temperature, respectively. Solutions of $7.2 \times 10^{-4}$ base molar GGA/GA and PGA in aqueous solution containing $1.0 \times 10^{-3} \mathrm{M} \mathrm{KCl}$ were used.

\section{RESULTS AND DISCUSSION}

\section{Conformation of $G G A / G A$ in Aqueous Solution}

Poly $(\gamma$-L-glutamyl-L-glutamic acid), the $100 \%$ modified polymer, could be obtained by the above procedure. However, the complete introduction of dicarboxylic acid residues prevented the satisfactory formation of the $\alpha$-helix in aqueous solution even at extremely low $\mathrm{pH}$.

We selected poly $(\gamma$-L-glutamyl-L-glutamic acid-co-L-glutamic acid) (GGA/GA) containing $66 \mathrm{~mol} \%$ dicarboxylic acid (GGA) residues. The reasons are as follows:

(i) The $66 \%$ GGA copolypeptide conserved the typical $\alpha$-helical-random coil transition induced by environmental $\mathrm{pH}$ change.

(ii) The probability of GGA residues between $j$ th and $(j+3)$ rd or $(j+4)$ th units, i.e., the close-neighboring side chain positions in the $\alpha$-helix conformation, is approximately $90 \%$ even when GGA content is $66 \%$.

These characteristics mean that the $66 \%$ GGA copolypeptide may be useful for the dicarboxylic acid containing proteins. ${ }^{12,13}$

Figure 1 shows the circular dichroism (CD) spectra of GGA/GA at various $\mathrm{pHs}$. It is apparent that GGA/GA exhibited a typical $\mathrm{pH}$-induced $\alpha$-helix-random coil transition. The double minimums at 222 and $208 \mathrm{~nm}$ in the CD spectra at pH 3.5 imply that no intermolecular association of $\alpha$-helical GGA/ GA occurs. ${ }^{25}$ The midpoint $\mathrm{pH}$ of transition about 4.7 was evaluated by $\mathrm{pH}$ dependence of $[\theta]_{222}$ shown in Figure 2. The $\alpha$-helix structure of GGA/GA was somewhat unstable compared with that of PGA (the broken line in Firue 2) owing to the larger electrostatic 


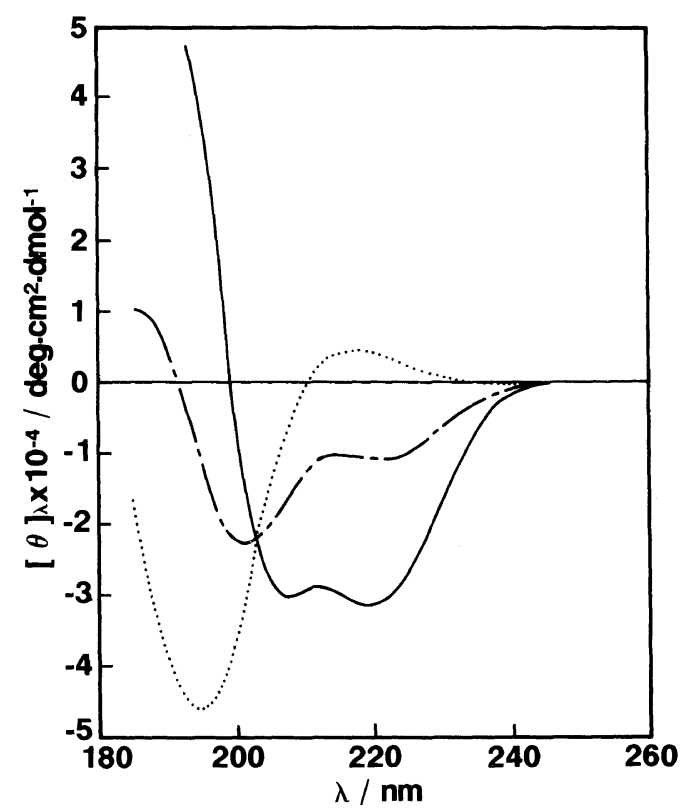

Figure 1. Circular dichroism spectra of GGA/GA in aqueous solution at various $\mathrm{pH}$. (-), $\mathrm{pH} 3.5 ;(--), \mathrm{pH}$ $5.0 ;(\cdots), \mathrm{pH} 7.0$.

repulsion force between dicarboxylic acid residues.

Complex Formation of $G G A / G A$ with $\mathrm{Cu}^{2+}$ Ion When $\mathrm{Cu}^{2+}$ ion was added to GGA/GA aqueous solution of various $\mathrm{pH}$, new absorption bands appeared at about $250 \mathrm{~nm}$ and $710 \mathrm{~nm}$ (Figure 3). The absorption band at $250 \mathrm{~nm}$ corresponds to the band at $250 \mathrm{~nm}$ of $\mathrm{Cu}$-acetate. ${ }^{26}$ The band could be assigned to the charge transfer (CT) from $\mathrm{RCOO}^{-}$to $\mathrm{Cu}^{2+}$. This CT band was observed with the PGA-Cu system at $250 \mathrm{~nm} \cdot{ }^{17,19,20}$ The latter band at $710 \mathrm{~nm}$ could be asigned to the $\mathrm{d}-\mathrm{d}$ transition of $\mathrm{Cu}^{2+}$ coordinated by carboxylates. ${ }^{17,19,20}$ Both wavelengths, 250 and $710 \mathrm{~nm}$, were not dependent on $\mathrm{pH}$ between 4.5-6.0. However, their intensities varied with $\mathrm{pH}$, indicating that the concentration and/or stability of the complex decreased with decreasing $\mathrm{pH}$, keeping the coordination structure almost uncharged. ${ }^{19}$ Furthermore, a shoulder band also appeared near $370 \mathrm{~nm}$.

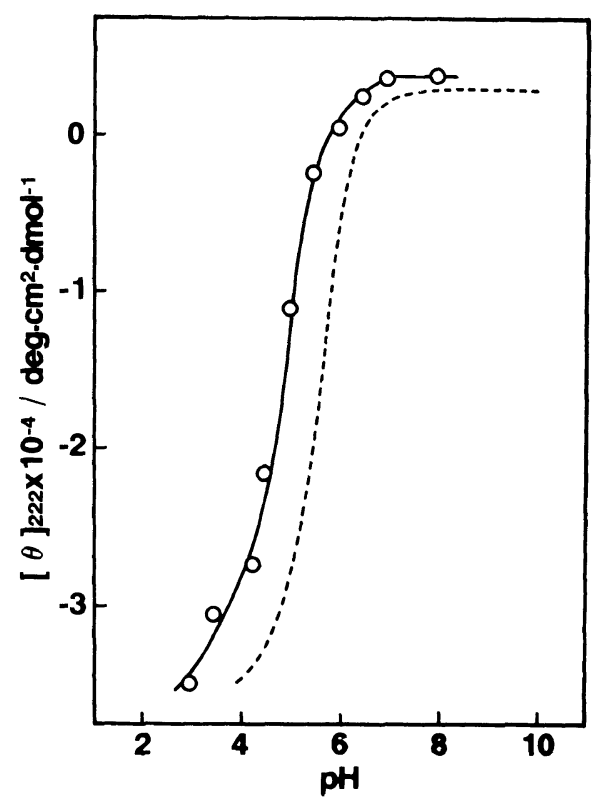

Figure 2. $\mathrm{pH}$ dependence of $[\theta]_{222}$ of GGA/GA and PGA in aqueous solutions. (- $\mathrm{O}-)$, GGA/GA; (----), PGA.

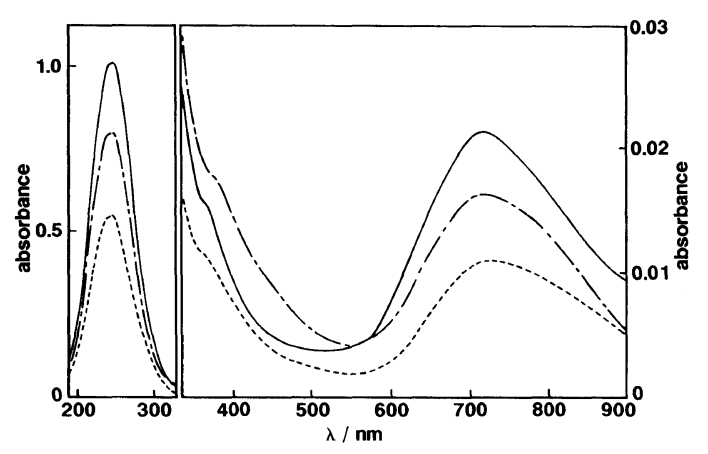

Figure 3. Absorption spectra of $\mathrm{GGA} / \mathrm{GA}-\mathrm{Cu}^{2+}$ in aqueous solution at various $\mathrm{pH} .(-), \mathrm{pH} 6.0 ;(---), \mathrm{pH}$ $5.0 ;(---), \mathrm{pH} 4.5 . R=[\mathrm{Cu}] /[\mathrm{COOH}]=0.25$.

This band may be associated with a characteristic dimeric structure of the $\mathrm{Cu}^{2+}$-acetate type. ${ }^{26-29}$ The shoulder band intensity at pH 5.0 was larger than that of $\mathrm{pH} 6.0$ even though the lower the $\mathrm{pH}$, the lower was complex stability. This difference is considered to be related to the backbone structure of the polypeptide as described below.

Figure 4 shows the absorption spectra of 


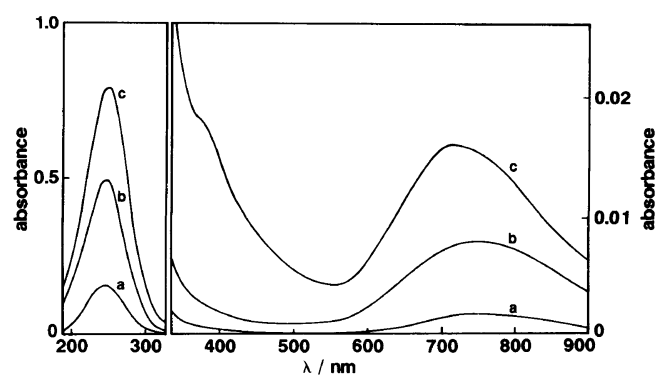

Figure 4. Absorption spectra of $\mathrm{GGA} / \mathrm{GA}-\mathrm{Cu}^{2+}$ in aqueous solutions at $\mathrm{pH} 5.0$. a, $R=0.05 ; \mathrm{b}, R=0.17$; , $R=0.25 . R=[\mathrm{Cu}] /[\mathrm{COOH}]$.

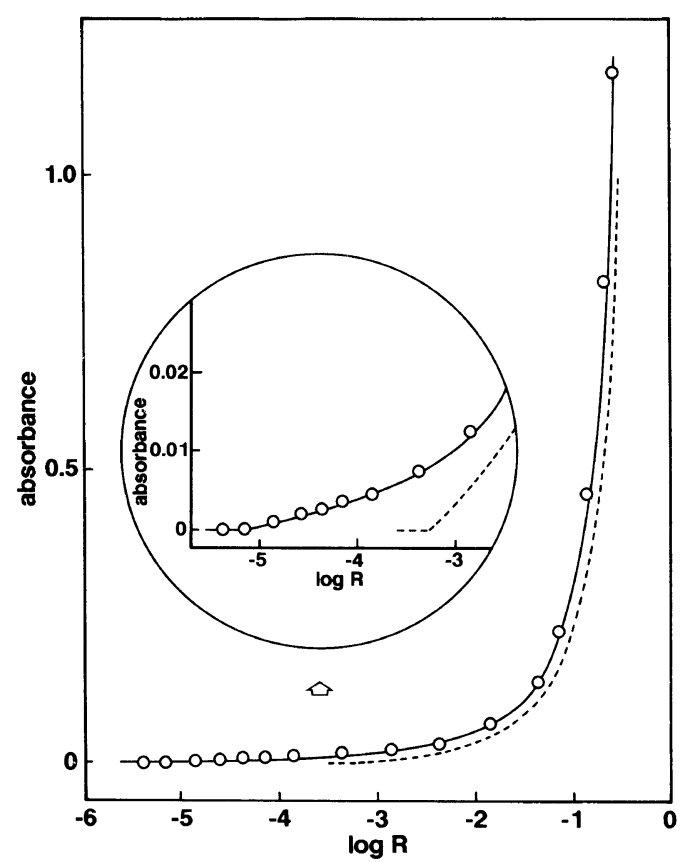

Figure 5. Changes in absorbance at $250 \mathrm{~nm}$ of GGA/$\mathrm{GA}-\mathrm{Cu}^{2+}(-\mathrm{O}-)$ and PGA- $\mathrm{Cu}^{2+}(----)$ in aqueous solution as a function of the mixing ratio, $R$.

GGA/GA- $\mathrm{Cu}^{2+}$ aqueous solutions at various mixing ratios of $\mathrm{Cu}^{2+}$ ion to carboxylic acid group in GGA/GA, $R=[\mathrm{Cu}] /[\mathrm{COOH}]$ at $\mathrm{pH}$ 5.0. The miximum wavelengths of the bands, 250 and $710 \mathrm{~nm}$, were almost independent of $\mathrm{Cu}^{2+}$ ion concentration. Figure 5 shows changes in absorbance at $250 \mathrm{~nm}$ as a function of $R$ with the results of PGA at $\mathrm{pH}$ 5.0. It is clear that the absorption intensity at

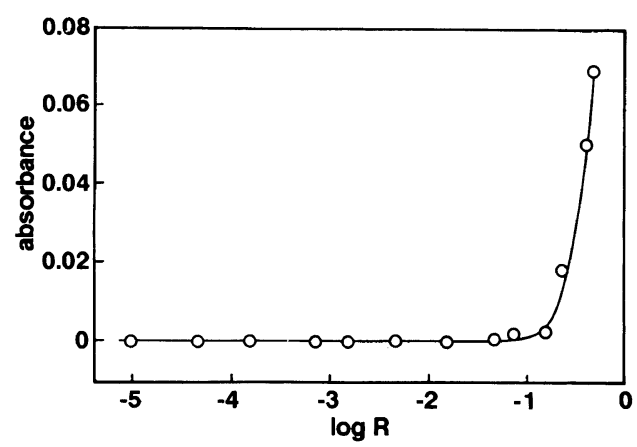

Figure 6. Changes in absorbance at $370 \mathrm{~nm}$ of GGA/$\mathrm{GA}-\mathrm{Cu}^{2+}$ in aqueous solutions as a function of the mixing ratio, $R$.

$250 \mathrm{~nm}$ was larger in $\mathrm{GGA} / \mathrm{GA}-\mathrm{Cu}^{2+}$ than in PGA- $\mathrm{Cu}^{2+}$ at the same $R$. The dicarboxylic acid-containing polypeptide, GGA/GA, thus has higher complex formation ability with $\mathrm{Cu}^{2+}$ ion than PGA. As seen in the insert, the minimum $\mathrm{Cu}^{2+}$ concentration required to induce formation of the GGA/GA- $\mathrm{Cu}^{2+}$ complex, $0.01 \mu \mathrm{M}$, was lower than of PGA$\mathrm{Cu}^{2+}, 0.5 \mu \mathrm{M}$. Thus the sensitivity of the dicarboxylic acid to $\mathrm{Cu}^{2+}$ ion is 50 times that of the monocarboxylic type. Furthermore, when the $\mathrm{Cu}^{2+}$ ion concentration exceeded $R=0.25$, a shoulder band appeared near $370 \mathrm{~nm}$ associated with the dimeric $\mathrm{Cu}^{2+}$ structure. Changes in the aborbance at $370 \mathrm{~nm}$ as a function of the mixing ratio, $R$, are shown in Figure 6. Beyond the threshold value about $R=0.16$, intensity increased significantly. To examine the relation between backbone structure and shoulder band intensity at $370 \mathrm{~nm}$, changes in $\alpha$-helix content estimated from the molecular ellipticity at $222 \mathrm{~nm}$ of GGA/GA in aqueous solution were plotted as a function of the mixing ratio, $R$ (Figure 7). It is apparent that conformational change of GGA/GA was also induced above $R=0.16$; that is, $\mathrm{Cu}-\mathrm{Cu}$ dimerization may be synchronized with the conformational transition to the $\alpha$-helical structure. When the mixing ratio of $\mathrm{Cu}^{2+}$ ion to carboxylic acid group in GGA/GA exceeds 0.16 , complexing $\mathrm{Cu}^{2+}$ ions compensate for the 


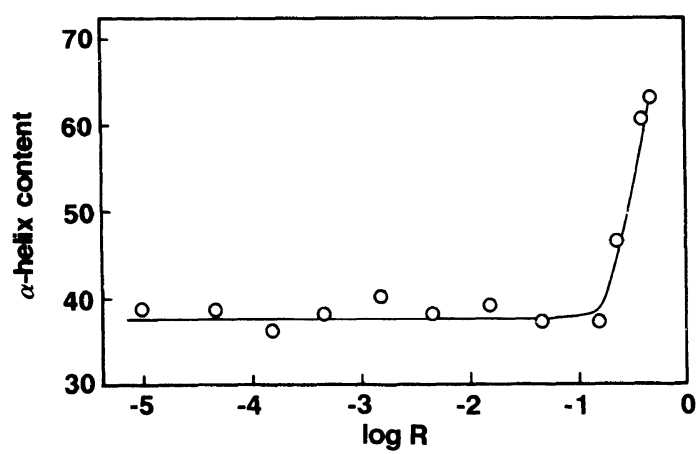

Figure 7. Changes in $\alpha$-helix content of GGA/GA in aqueous solution as a function of $R$.

anioinc repulsion between dicarboxylic acid side chains, which results in the random coil to $\alpha$-helix transition of the polypeptide. The transition to the compact structure, $\alpha$-helical structure, brought the side chains between $j$ th and $(j+3)$ rd or $(j+4)$ th residues so close together, that $\mathrm{Cu}-\mathrm{Cu}$ interactions became possible. The characteristic dimeric structure of $\mathrm{Cu}^{2+}$ may thus be produced in the sidechain region (Figure 8 ). Though PGA was in the $\alpha$-helix conformation (ca. 92\%) at $\mathrm{pH} 5.0$, the absorbance of the shoulder at $370 \mathrm{~nm}$ was only about 0.012 at $R=0.26$, corresponding to the maximal mixing ratio in Figure 6 . Therefore, the remarkable increase of the band in Figure 6 was effectively caused by dimeric $\mathrm{Cu}^{2+}$ complexation formed between adjacent side-chain dicarboxylic acid groups. That the dicarboxylic acid residues were appreciably present on the peripheryl of the $\alpha$-helix domain in GGA/GA was thus experimentally confirmed again. The difference in the shoulder bands intensity between $\mathrm{pH} 5.0$ and 6.0 at $R=0.25$ (Figure 3) is also accounted for by $\alpha$-helix content of GGA/GA at pH 5.0, 47\%, being higher than that at $\mathrm{pH} 6.0,26 \%$. Moreover, cross-links of side chains based on the dimeric structure of $\mathrm{Cu}^{2+}$ may increasingly stabilize the $\alpha$-helix structure of the polypeptide. ${ }^{30}$ The steep rise of helix content in Figure 6 supports the idea that the induced $\alpha$-helical structure may be explained as due to the co-

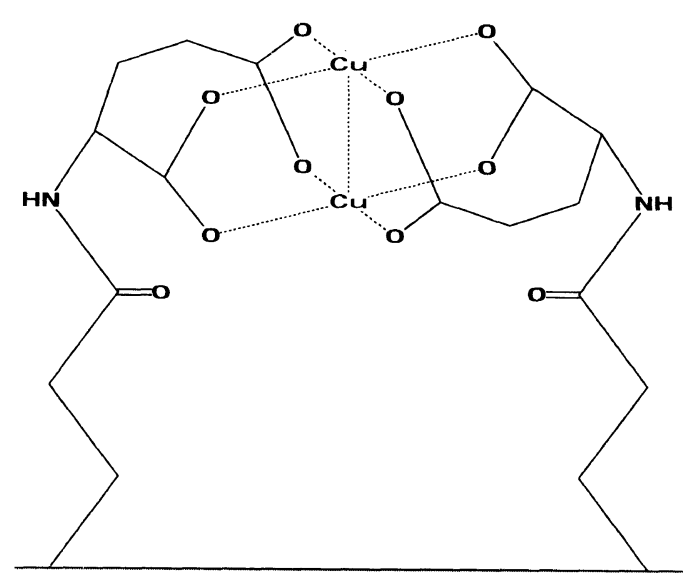

$$
\alpha \text {-helix }
$$

Figure 8. Schematic presentation of anticipated $\mathrm{Cu}^{2+}$ GGA/GA complexes.

operative effect between the neutralization of $\mathrm{Cu}^{2+}$ for $\mathrm{GGA}$ residues and the $\mathrm{Cu}-\mathrm{Cu}$ dimeric linkage.

In conclusion, complex formation between $\mathrm{Cu}^{2+}$ ion and dicarboxylic acid-containing polypeptide in aqueous solution could be observed even at extremely low $\mathrm{Cu}^{2+}$ concentration by the absorption method. Furthermore, the backbone structure of the polypeptide is remarkably affected by copper ion complexation. Such specific complex formation accompanying conformational change may also be useful for constructing bio-mimetic macromolecular systems possessing metal ions.

Acknowledgements. This work was partly supported by a Grant-in-Aid for Scientific Research from the Ministry of Education, Science, and Culture of Japan.

\section{REFERENCES}

1. J. Stenflo, P. Fernlund, W. Egan, and P. Roepstorff, Proc. Natl. Acad. Sci. U.S.A., 71, 2730 (1974). 
2. P. A. Price, A. S. Otsuka, J. W. Poser, J. Kristaponis, and N. Raman, Proc. Natl. Acad. Sci. U.S.A., 73, 1447 (1976).

3. B. C. Furie, M. Blumenstein, and B. Furie, J. Biol. Chem., 254, 12521 (1979).

4. R. W. Romberg, P. G. Werness, B. L. Riggs, and K. G. Mann, Biochemistry, 25, 1176 (1986).

5. B. Furie and B. C. Furie, Cell, 53, 505 (1988).

6. J. S. Pollock, A. J. Shepard, D. J. Weber, D. L. Olson, D. G. Klapper, L. G. Pedersen, and R. G. Hiskey, J. Biol. Chem., 263, 14216 (1988).

7. M. Soriano-Garcia, C. H. Park, A. Tulinsky, K. G. Ravichandran, and E. Skrzypczak-Jankun, Biochemistry, 28, 6805 (1989).

8. A.-K. Öhlin, I. Björk, and J. Stenflo, Biochemistry, 29, 644 (1990).

9. M. Hessing, Biochem. J., 277, 581 (1991).

10. E. Persson, I. Björk, and J. Stenflo, J. Biol. Chem., 266, 2444 (1991).

11. M. Soriano-Garcia, K. Padmanabhan, A. M. de Vos, and A. Tulinsky, Biochemistry, 31, 2554 (1992).

12. P. V. Hauschka and S. A. Carr, Biochemistry, 21, 2538 (1982).

13. M. H. J. Knapen, K. Hamulyák, C. Vermeer, Ann. Int. Med., 111, 1001 (1989).

14. S. Inoue, K. Yamaoka, and M. Miura, Bull. Chem. Soc. Jpn., 44, 1443 (1971).

15. S. Inoue, K. Yamaoka, and M. Miura, Bull. Chem. Soc. Jpn., 45, 1314 (1972).

16. S. Noji and K. Yamaoka, Macromolecules, 12, 1110
(1979).

17. K. Yamaoka and T. Masujima, Bull. Chem. Soc. Jpn., 52, 1286 (1979).

18. T. Hiraoki, M. Kaneko, and K. Hikichi, Polym. J., 11, 397 (1979).

19. T. Masujima and K. Yamaoka, Biopolymers, 19, 477 (1980).

20. M. Koide, E. Tsuchida, and Y. Kurimura, Macromol. Chem., 182, 359 (1981).

21. H. Maeda, T. Hiramatsu, and S. Ikeda, Bull. Chem. Soc. Jpn., 59, 587 (1986).

22. M. Sato, T. Kinoshita, A. Takizawa, and Y. Tsujita, Macromolecules, 21, 3419 (1988).

23. T. Kinoshita, T. Yamashita, T. Iwata, A. Takizawa, and Y. Tsujita, J. Macromol. Sci., B22, 1 (1983).

24. P. B. Ghosh and M. W. Whitehouse, Biochem. J., 108, 155 (1968).

25. O. Pieroni, A. Fissi, J. L. Houben, and F. Ciardelli, J. Am. Chem. Soc., 107, 2990 (1985).

26. M. Kato, H. B. Jonassesn, and J. C. Fanning, Chem. Rev., 64, 99 (1964).

27. S. Kida, Y. Nakashima, Y. Morimoto, K. Niimi, and S. Yamada, Bull. Chem. Soc. Jpn., 37, 549 (1964).

28. A. E. Hansen and C. J. Ballhausen, Trans. Faraday Soc., 61, 631 (1965).

29. L. Dubicki and R. L. Martin, Inorg. Chem., 5, 2203 (1966).

30. F. Ruan, Y. Chen, and P. B. Hopkins, J. Am. Chem. Soc., 112, 9403 (1990). 